\title{
Human Fetal Liver Stromal Cells That Overexpress bFGF Support Growth and Maintenance of Human Embryonic Stem Cells
}

\author{
Jiafei Xi, Yunfang Wang, Peng Zhang, Lijuan He, Xue Nan, Wen Yue ${ }^{* \boldsymbol{9}}$, Xuetao Pei ${ }^{* \boldsymbol{9}}$
}

Stem Cell and Regenerative Medicine Lab, Beijing Institute of Transfusion Medicine, Beijing, China

\begin{abstract}
In guiding hES cell technology toward the clinic, one key issue to be addressed is to culture and maintain hES cells much more safely and economically in large scale. In order to avoid using mouse embryonic fibroblasts (MEFs) we isolated human fetal liver stromal cells (hFLSCs) from 14 weeks human fetal liver as new human feeder cells. hFLSCs feeders could maintain hES cells for 15 passages (about 100 days). Basic fibroblast growth factor (bFGF) is known to play an important role in promoting self-renewal of human embryonic stem (hES) cells. So, we established transgenic hFLSCs that stably express bFGF by lentiviral vectors. These transgenic human feeder cells - bFGF-hFLSCs maintained the properties of H9 hES cells without supplementing with any exogenous growth factors. H9 hES cells culturing under these conditions maintained all $\mathrm{hES}$ cell features after prolonged culture, including the developmental potential to differentiate into representative tissues of all three embryonic germ layers, unlimited and undifferentiated proliferative ability, and maintenance of normal karyotype. Our results demonstrated that bFGF-hFLSCs feeder cells were central to establishing the signaling network among bFGF, insulin-like growth factor 2 (IGF-2), and transforming growth factor $\beta$ (TGF- $\beta$ ), thereby providing the framework in which hES cells were instructed to self-renew or to differentiate. We also found that the conditioned medium of bFGF-hFLSCs could maintain the H9 hES cells under feeder-free conditions without supplementing with bFGF. Taken together, bFGF-hFLSCs had great potential as feeders for maintaining pluripotent hES cell lines more safely and economically.
\end{abstract}

Citation: Xi J, Wang Y, Zhang P, He L, Nan X, et al. (2010) Human Fetal Liver Stromal Cells That Overexpress bFGF Support Growth and Maintenance of Human Embryonic Stem Cells. PLoS ONE 5(12): e14457. doi:10.1371/journal.pone.0014457

Editor: Rafael Linden, Universidade Federal do Rio de Janeiro, Brazil

Received December 30, 2009; Accepted December 7, 2010; Published December 30, 2010

Copyright: ( ) $2010 \mathrm{Xi}$ et al. This is an open-access article distributed under the terms of the Creative Commons Attribution License, which permits unrestricted use, distribution, and reproduction in any medium, provided the original author and source are credited.

Funding: This work was supported by National High Technology Research and Development Program of China (No: 2006AA02A107 to X.T.P.), the Major State Basic Research Program of China (No: 2009 CB941102 to W.Y. and No: 2011 CB964804 to W.Y.), and the Project of Beijing Municipal Science \& Technology Commission (No: D07050701350702 to X.T.P.). The funders had no role in study design, data collection and analysis, decision to publish, or preparation of the manuscript.

Competing Interests: The authors have declared that no competing interests exist.

*E-mail: wenyue26@yahoo.com (WY); peixt@nic.bmi.ac.cn (XP)

9 These authors contributed equally to this work.

\section{Introduction}

Human embryonic stem (hES) cells are pluripotent cells derived from the inner cell mass of blastocyst-stage human embryos [1,2]. They can be expanded indefinitely as undifferentiated cells for extended periods of time, and possess the capacity to generate all cell types in the body. To date, many of the studies have highlighted the success in differentiating cell populations from hES cells for cell replacement therapy [3,4]. However, in guiding hES cell technology toward the clinic, one key issue to be addressed is to culture and maintain hES cells much more safely and economically in large scale. hES cells are most commonly maintained on inactivated mouse embryonic fibroblasts (MEFs) feeders in medium supplemented with knockout serum-replacement (KSR) together with basic fibroblast growth factors (bFGF, or FGF 2). These xeno-support systems run the risk of crosstransfer of animal pathogens from the animal feeder. One example is hES cells cultured with animal products that express Neu5Gc, as a nonhuman sialic acid that triggers an immunogenic response [5].

In order to avoid the use of MEFs, human feeders has been used as an alternative method to maintain hES cells, including embryonic fibroblasts, adult fallopian tube epithelium [6], bone marrow stromal cells [7], foreskin fibroblasts [8], human cell lines (D551/CCL-10, CCL-2552), adult skin cells [9], and placenta cells [10]. But recently, Rajala et al. test nine previously reported xenofree culture media formats, and conclud that none could maintain the undifferentiated growth of hES cells [11]. So more effective human feeder cells should be selected by comparing each type of feeder cell for their capability to support the growth and maintenance of hES cells. hES cells established on the most effective human feeder cells will apparently promote the development of cell-based therapies.

The other systems to avoid using MEFs as feeders is to use a feeder-free environment that cultures hES cells in special media supplemented with Matrigel matrix [12] or fibronectin [13]. However, some require culture on Matrigel but this contains a variety of extracellular matrix (ECM) components, most likely associated with an ill-defined mixture of growth factors [13,14,15]. Recently, successful attempts have been made to develop chemically defined culture medium $[16,17,18,19]$. In the most present study, the authors introduce a defined serum free medium, hESF9, in which bFGF was the only protein components [19]. 
Nevertheless, there is no consensus as to the optimal formulation of the chemically defined medium. Moreover, it is likely that feeder-free culture are not optimal for developing transplantable hES cell derivative, for feeder-free cultures usually display a higher degree of spontaneous differentiation than conventional culture. And feeder-free systems, using bFGF and other additional growth factors, will significantly increase the cost of the hES cell culture. So, it is not suitable to use in large scale expansion of hES cells for clinical applications. For the time being, the use of feeder cells is still the safest and most cost-effective option to derive and propagate stable hES cells.

Despite the evolution of these culture conditions and the addition of several factors, all require supplementation with bFGF to sustain hES cell potential. bFGF appears to be of similar importance for hES cells self-renewal as leukemia inhibitory factor (LIF) is for mouse ES cells [20]. But the basis to using bFGF to maintain hES cells still remains unknown. In a previous study, very high concentrations of bFGF (up to $100 \mathrm{ng} / \mathrm{ml}$ ) was used to maintain hES cells [21], this suggests that either bFGF is operating through an receptor that it is relatively unstable or inefficiently presented to the cells in the culture conditions used. On the other hand, it is supposed that bFGF acts on MEFs to release supportive factors and to reduce differentiation- inducing activity. It is suggested that that bFGF, at least in part, promotes self-renewal of hES cells by modulating the expression of transforming growth factor $\beta$ (TGF- $\beta$ ) ligands, which, in turn, act on hES cells in autocrine manner [22]. In a most present study, insulin-like growth factor 2 (IGF-2) is expressed by autologously derived hES cell fibroblast-like cells ( $\mathrm{hdFs}$ ) in response to bFGF, and alone was sufficient in maintaining hES cell cultures. This study establishes that hdFs produced by hES cells themselves define the stem cell niche of pluripotent human stem cells. The study reveals a previously unappreciated but essential celluar interplay that establishes a paracrine signaling as being required for pluripotency of hES cells [23]. So, it would be possible to establish more effective hES cell culture system by mimicking the stem cell niche for pluripotency.

In the present study, we had now investigated the culture of $\mathrm{H} 9$ hES cells on a new human feeder cells - human fetal liver stromal cells (hFLSCs). The new feeder cells permitted H9 hES cells prolonged culture in an undifferentiated state. In particular, we had established a transgenic feeder cells-bFGF-hFLSCs that stably express bFGF by lentiviral systems, which could be used to maintain H9 hES cells without any exogenous growth factors. And the bFGFhFLSCs specifically express high levels of bFGF and IGF-2, which are the key factor supports hES cells in culture. And hES cells are successfully maintained feeder-free with conditioned medium of bFGF-hFLSCs (bFGF-hFLSGs-GM). Thus, bFGF-hFLSGs were a novel population that was capable of supporting hES cells expansion more effectively and economically. And also the new culture system could be used as an in vitro model to study comprehensive mechanisms of hES cell self-renewal and pluripotency.

\section{Materials and Methods}

\section{Isolation of hFLSCs}

hFLSCs were obtained from 14 weeks human fetal liver tissues as described previously [24]. Human tissue collection for research purpose was approved by Research Ethics Committee of Beijing Institute of Transfusion Medicine. Pregnant women gave written consent for clinical procedure and research use of the embryonic tissues in accordance with the Declaration of Helsinki. hFLSGs were cultured in a medium comprising $45 \%$ Dulbecco's modified Eagle's medium (DMEM, Sigma-Aldrich, St. Louis), 45\% DMEM/F12 (Sigma-Aldrich), and supplemented with 10\% FCS (fetal calf serum; Gibco, Grand Island, NY). Briefly, hFLSCs were prepared using a ceiling culture method. Human fetal liver tissues were minced into $1 \mathrm{~mm}^{3}$ pieces, and transferred onto human gelatin-coated $25-\mathrm{cm}^{2}$ flasks. $4 \mathrm{~mL}$ of hFLSCs culture medium was added onto the ceiling surface, and after $5 \mathrm{~h}$ the flasks were turned back over. The tissue pieces were incubated undisturbed for 7 days at $37^{\circ} \mathrm{C}$, allowing the hFLSCs to migrate and adhere to the gelatin-coated surface. Once the primary hFLSCs reached confluency, the hFLSG were digested with $0.25 \%$ Trypsin (Sigma-Aldrich) for $5 \mathrm{~min}$ at $37^{\circ} \mathrm{C}$. After adding hFLSCs medium, cultures were pipetted into single-cell suspensions, centrifuged, resuspended, and replated onto new flasks.

\section{Establishment and Characterization of Transgenic hFLSCs that Overexpressing bFGF}

hFLSCs that stably express bFGF were established as previously described [24]. Briefly, bFGF cDNA was cloned from human Mesenchymal stem cells (MSGs) using RT-PCR. Then the amplified human bFGF fragments was ligated into a pBPLV lentiviral vector plasmids containing eGFP [25] (kindly provided by Dr. Luigi Naldiai, Vita Salute San Raffaele University, Italy) (supporting information Fig. S1). The lentiviruses were assembled in 293-FT cells lines (Invitrogen). hFLSCs were seeded at $5 \times 10^{5}$ cells per $25-\mathrm{cm}^{2}$ flasks one day before transduction. The medium was replaced with virus-containing supernatant supplemented with $4 \mu \mathrm{g} / \mathrm{ml}$ polybrene (Sigma-Aldrich), and incubated for $48 \mathrm{~h}$. After $48 \mathrm{~h}$ of transfecction, the eGFP positive hFLSCs that constitutively expressed bFGF were sorted by fluorescence-activated cell sorting (FACS) according to the low and high intensity of eGFP expression.

\section{General hES Cell Culture}

hES cells (H9; WiCell Research Institute, Madison, WI) were cultured according to the supplier's instructions. Briefly, hES cells were routinely cultured on CDl MEFs in knockout (KO)DMEM/F12 (Invitrogen, Carlsbad, CA) containing 20\% KSR(Invitrogen), $2 \mathrm{mM}$ L-glutamine, $100 \mu \mathrm{M}$ nonessential amino acids (NEAA, Invitrogen), $100 \mu \mathrm{M} \quad \beta$-mercaptoethanol (Invitrogen), $4 \mathrm{ng} / \mathrm{mL}$ bFGF (Peprotech, Rocky Hill, NJ) and $0.5 \%$ penicillin and streptomycin. The medium was changed every day.

\section{Culture of hES Cells on hFLSCs and bFGF-hFLSCs}

The hFLSGs with or without the bFGF transgene were irradiated (40 Gy of ${ }^{60} \mathrm{Co}-\gamma$ ) within twenty generations and frozen in liquid nitrogen. Before passaging, the hFLSCs were thawed and replated into 6 well cell culture plate at the density of $1 \times 10^{6}$ per well to be feeders. After $24 \mathrm{~h}$, the culture medium was replaced with hES cell culture medium and hES cells could be seeded on the feeders. hES cells cultured on hFLSCs or bFGF-hFLSGs were passaged every one week by mechanical harvesting.

hES cell culture medium for hFLSCs feeders was identical to the medium used in MEFs feeders, and the medium were changed daily. hES cell culture medium for bFGF-hFLSCs feeders was also identical to the medium used in MEFs feeders but removal of the bFGF, and the medium were changed daily by partial medium changes.

\section{Characterization of hES cells by Flow Cytometry}

Single-cell suspensions were made from undifferentiated hES cells. Stained cells were analysed on a FACS Calibur using Cell Quest software (BD Biosciences, San Diego). Unconjugated antibody against Stage-specific embryonic antigen 4 (SSEA4) (Chemicon, Temecula, CA), tumor-related antigen 60 (TRA-1-60) (Chemicon), and OCT4 (Chemicon) were used to viably identify 
hES cells. Then hES cells were washed twice prior to staining with fluorescein isothiocyanate (FITC)-conjugated goat anti-mouse IgG (BD Biosciences) for $30 \mathrm{~min}$. Finally, the cells were washed twice with PBS and analyzed by flow cytometery. Negative controls represented staining of cells in the absence of primary antibody.

\section{Embryoid Bodies (EBs)-mediated In Vitro Differentiation of hES Cells Cultured on bFGF-hFLSCs}

For EBs formation, H9 hES cells were harvested by treating with collagenase IV. The clumps of the cells were transferred to 6well Ultra-Low Attachment Plate (Corning, NY) in DMEM/F12 containing 20\% KSR (Invitrogen), $2 \mathrm{mM}$ L-glutamine, $100 \mu \mathrm{M}$ NEAA (Invitrogen), $100 \mu \mathrm{M}$-mercaptoethanol (Invitrogen), and $0.5 \%$ penicillin and streptomycin. The medium was changed every other day. After 6 days as a floating culture, EBs were transferred to gelatin-coated plate and cultured in the same medium for another 10 days.

\section{Teratoma formation}

Approximately $5 \times 10^{6} \mathrm{H} 9$ hES cells cultured on bFGF-hFLSCs for 10 passages (about 70 days) with undifferentiated morphology were subcutaneously injected into the rear leg armpit of 6-8 weeks old Nonobese Diabetic/Severe Combined Immunodeficiency (NOD-SCID) mice. About 6-10 weeks after injection, teratoma formed and were dissected and fixed with $4 \%$ paraformaldehyde overnight. The samples were then cut at a thickness of $10 \mu \mathrm{m}$ and transferred to Poly-D-Lysine-coated slides. Sections were examined histologically after hematoxylin and eosin staining. All the animal experiments were approved by the Animal Care and Use Committee of Beijing Institute of Transfusion Medicine.

\section{Immunocytochemistry}

Cells were rinsed twice with PBS before fixation with 4\% paraformaldehyde, followed by protein staining before permeabilization with $0.2 \%$ Triton X-100 or $100 \%$ methanol and staining for OCT4. Cells were blocked with $10 \%$ normal rabbit serum or $10 \%$ normal goat serum at room temperature. Antibodies used were antiIGF1R (R\&D Systems, Minneapolis), anti-FGFR1 (Chemicon), antiOCT4 (Chemicon), anti-SSEA-4 (Chemicon), anti-TRA-1-60 (Chemicon), anti-TRA-1-81 (Chemicon), anti-3III-TUBULIN (BD Biosciences), anti- $\alpha$-SMA (BD Biosciences), and anti-AFP (SigmaAldrich). Cells were incubated with primary antibodies followed by secondary detection with FITC-conjugated goat anti-mouse IgG (BD Biosciences), or FITC-conjugated rabbit anti-goat IgG (BD Biosciences), or TRITC-conjugated goat anti-mouse IgG (BD Biosciences). Nucleuses were stained with $1 \mu \mathrm{g} / \mathrm{ml}$ DAPI (SigmaAldrich). Fluorescence was visualized using Olympus IX70 (Olympus, Tokyo) fluorescence microscope, and images were recorded using a digital SPOT RT3 CCD camera (Diagnostic Instruments inc., Sterling Heights, MI) using version 4.5 SPOT software.

\section{Feeder-free maintenance of hES cells in bFGF-hFLSCs- $\mathrm{CM})$}

hES cells lines H9 were maintained in a feeder-free culture over matrigel-coated (BD Biosciences) six-well plate in bFGF-hFLSCsCM. bFGF-hFLSCs-CM was prepared and collected as described in detail for MEF-CM $[12,26]$. The basal media used to prepare the CM consisted of $80 \%$ KO-DMEM/F12 supplemented with $20 \%$ KSR, 1\% NEAA, 1 mM L-glutamine, $0.1 \mathrm{mM} \beta$-mercaptoethanol. H9 hES cells was maintained feeder-free for 10-15 passages (about 70-100 days). The media was changed daily and the hES cells cultures were split (1:3) using collagenase IV. H9 hES cells were also cultured under feeder free conditions using MEF-CM [26] and
mTeSR1(StemCell Technologies, Vancouver, BC, Canada) following the manufacturer's instructions.

\section{Reverse Transcription-Polymerase Chain Reaction Analysis}

Total RNA was extracted by TRIzol reagent (Invitrogen) according to the manufacturer's instructions. $1 \mu \mathrm{g}$ RNA was then reverse-transcribed into cDNA by Avian Myeloblastosis Virus (AMV) reverse transcriptase (Takara Bio, Shiga, Japan). PCR was performed with rTaq polymerase (TaKaRa). An aliquot of PCR products was analyzed on $1.5 \%$ ethidium bromide-stained agarose. Glyceraldehyde-3-phosphate dehydrogenase (GAPDH) or $\beta$-actin was used as a housekeeping gene to evaluate and compare quality of different cDNA samples.

\section{RT-PCR Primer Sequences}

The following primer pairs were used for the amplification of target mRNAs: Oct-4 (123 base pair [bp]), forward 5' - AAC CTG GAG TTT GTG CAA GGG TTT-3' and reverse 5' - TGA ACT TCA GCT TCG CTC CAA CGA-3'; Sox-2 (151 bp), forward 5'GGG AAA TGG GAG GGG TGC AAA AGA GG-3' and reverse 5' - TTG CGT GAG TGT GGA TGG GAT TGG TG3'; Nanog (216 bp), forward 5'- CAG AAG GCC TCA GCA CCT-3' and reverse 5' - CTG TTG CAG GCG TGA TTG TT3'; HCG (510 bp), forward 5' - CAG GGG AGG CAC CAA GGA TG-3' and reverse 5' - GTG GGA GGA TCG GGG TGT CG-3'; CK18 (233 bp), forward 5' - AGG TGA ACG GGA TCG TGG TGG ACG TTG-3' and reverse 5' - CAC TAT CGG GGG GGT GGT GGT CTT TTG-3'; AFP (281 bp), forward 5' - GAA TGG TGG AAA CTG ACG ACG CTG GAA C-3' and reverse 5'TGG CAT TGA AGA GGG TTT TGA GTG TGG A-3'; Brachyury (144 bp), forward 5'- TGT CGG AGG TGG CTT ACA GAT GAA-3' and reverse 5' - GGT GTG CGA AAG TTG CCA ATA CAC-3'; PAX6 (317 bp), forward 5' - ACG CAT TAT CAA GAT GTG TTT GCA CGA G-3' and reverse 5'- ATG GTG AAG CTG GGC ATA GGC GGC AG-3'; GFAP (328 bp), forward 5' - GGC CCG CCA CTT GGA GGA GTA CGA GG$3^{\prime}$ and reverse 5' - CTT CTG CTC GGG CGC CTG ATG AGA CG-3'; bFGF (486 bp), forward 5' - AAC TGG AGA TGG CAG CGG GGA GCA TC- $3^{\prime}$ and reverse 5' - ACG CGT CGA CTG AGC TCT TAG CAG ACA TTG GAA GAA-3'; IGF-1 (184 bp), forward 5'- GGT GGT GGA TGC TCT TCA GTT C-3' and reverse 5' - AGG TGA CTT GGG AGG CTT GAG-3'; IGF-2 (150 bp), forward 5'- TTG CTG TAG CGA CGC AAG AC-3' and reverse 5' - GAT GGA ACC TGA TGG AAA CG-3'; TGF$\beta 1$ (221 bp), forward 5' - GCG TGC TAA TGG TGG AAA C-3' and reverse 5'- GCT GAG GTA TCG CCA GGA AT-3'; IGF1 receptor (99 bp), forward 5' - CGA AAG ACA AAA TCG CGA TC-3' and reverse 5'- CTT TCT CGC CAC CAC ACA C-3'; FGF receptor 1 (119 bp), forward 5'- GGC TAG AAG GTC CGT TAT GC-3' and reverse 5' - TGG TAT GTG TGG TTG ATG CTG-3'; $\beta$-actin (222 bp), forward 5'- GAT CGA CAT CTG CTG GAA GG-3' and reverse 5' - AAG TGT GAC GTT GACATC CG-3'; GAPDH (325 bp), forward 5'- TGT CAT CAA TGG AAA TGG CAT CAG C-3' and reverse 5'- CAT GAG TCG TTC CAC GAT ACG AAA-3'.

\section{Protein Extraction and Western Blotting}

Protein extracts were obtained using RIPA lysis buffer $(50 \mathrm{mM}$ Tris-HCl pH 7.4; $150 \mathrm{mM} \mathrm{NaCl} ; 1 \%$ NP-40; $0.1 \%$ SDS; $0.5 \%$ Na-deoxycholale) with protease inhibitor (Merk Chemicals, Darmstadt, Germany). Cell lysates were cleared at 12,000 g for 10 minutes at $4^{\circ} \mathrm{C}$. Equal amounts of proteins in the supernatants 
A

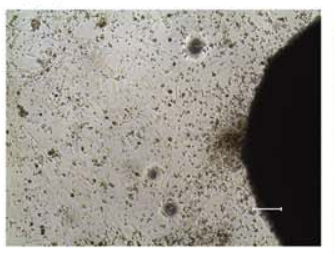

B

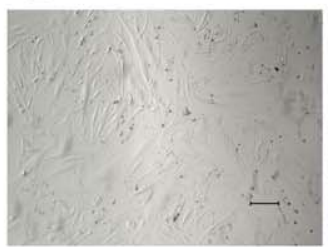

E
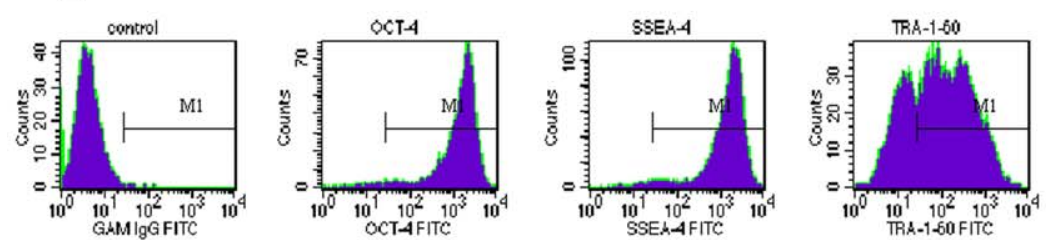

$\mathrm{F}$
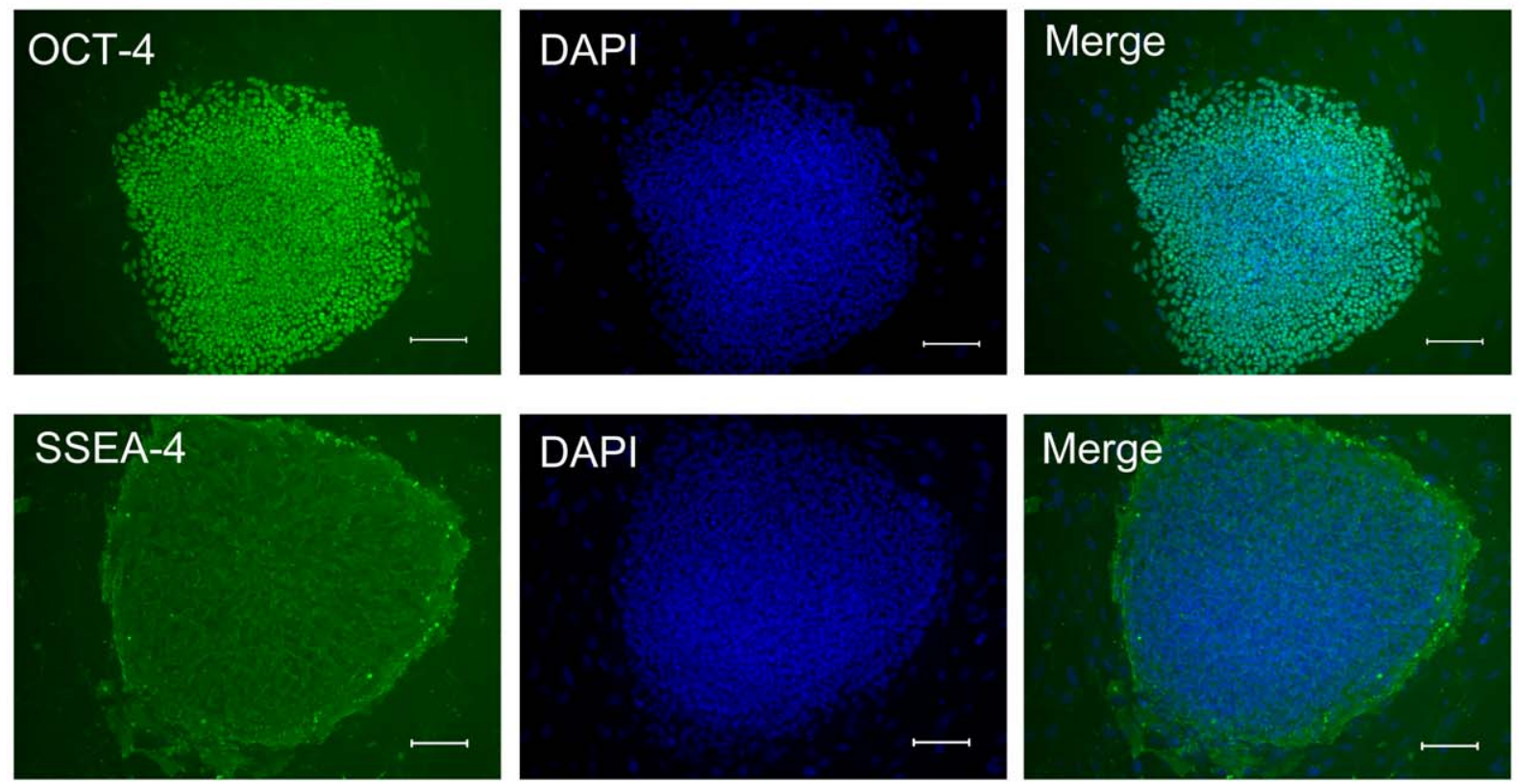

D

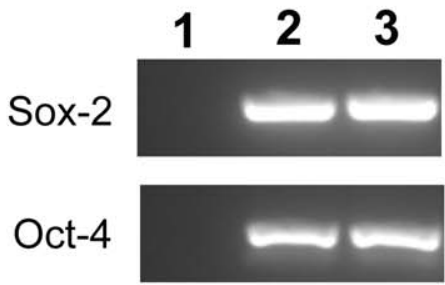

RT-

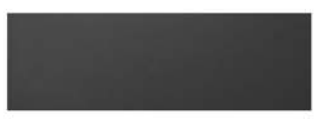

$\beta$-actin

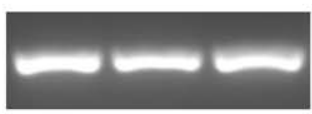

\section{Merge}

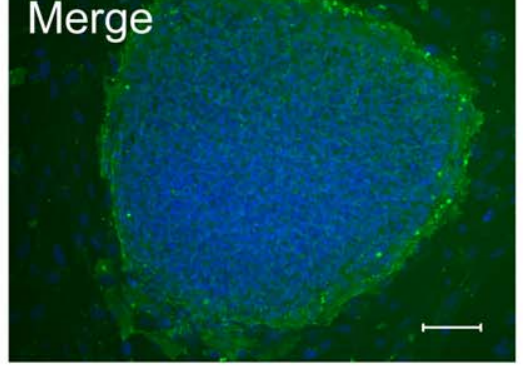

Figure 1. Morphology and characterization of H9 hES cells grown on hFLSCs. (A): Derivation of hFLSCs by ceiling culture method. (B): hFLSCs show typical fibroblast morphology. (C): Morphology of H9 hES cells grown on hFLSCs. (D): RT-PCR analysis of H9 hES cells grown on hFLSCs for 10 passages (about 70 days). 1: hFLSCs feeder cells, 2: H9 hES cells cultured on MEF, H9 hES Cells cutred on hFLSCs. (E): Cell phenotype analysis of $\mathrm{H} 9 \mathrm{hES}$ cells that cultured on hFLSCs for 10 passages (about 70 days) by flow cytometry.(F): H9 hES cells grown on hFLSCs for 15 passages (about 100 days) stained with antibody recognizing the OCT-4 and SSEA-4. Nuclei were stained with DAPI (blue). Bars: (A-C, F) $100 \mu \mathrm{m}$. doi:10.1371/journal.pone.0014457.g001

were separated on $12 \%$ SDS-PAGE and blotted on PVDF membrane (Bio-Rad, Hercules, CA). Membranes were blocked with $4 \%$ non-fat milk (Bio-rad)/TBS-T and incubated with an anti-bFGF antibody or anti-IGF-2 antibodies (all from R\&D Systems) followed by horseradish peroxidase (HRP)-conjugated secondary antibodies and visualized with ECL (Santa Cruz Biotechnology, Santa Cruz, CA) detection. Chemoluminescence was visualized on an $\mathrm{x}$-ray film.

\section{Enzyme-linked Immunosorbent Assays}

Free human bFGF was determined with the FGF basic ELISA kit (R\&D Systems). Assays were performed according to the manufacturer's recommended protocol. Protein extracted from culture supernatants were standardized for total protein content using the BCA Protein Assay kit (Pierce, Rockford, IL) before analysis. Results are representative of four independent experiments.

\section{Karyotype Analysis}

Karyotype analyses of $\mathrm{H} 9 \mathrm{hES}$ cells cultured on hFLSCs and bFGF-hFLSCs were carried out at passages 15 (about 100 days) using the standard G-banding procedure. The karyotype analyses were done at the Beijing Institute of Radiation Medicine, Cytogenetics Laboratory (Beijing, China). 
A
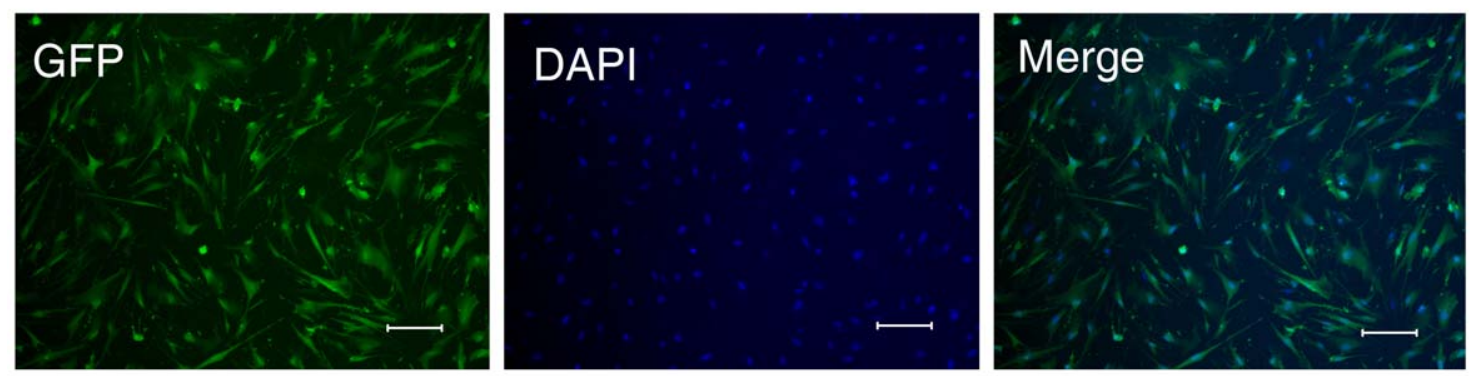

B
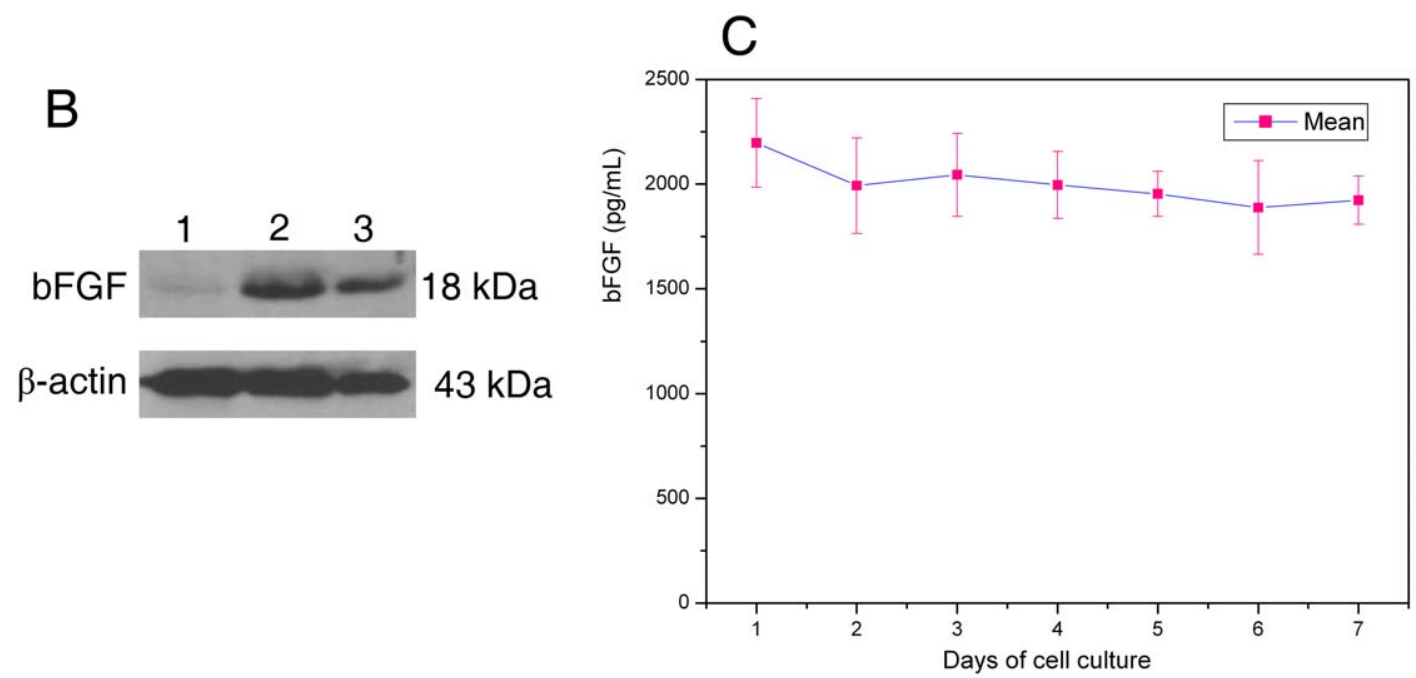

Figure 2. Morphology and identification of bFGF over-expressing hFLSCs feeder cells. (A): eGFP expression of $\gamma$-irradiated bFGF-hFLSCs imaged by fluorescence microscope. Bars: $100 \mu \mathrm{m}$. (B): Western blotting analysis indicated that bFGF highly expressed in $\gamma$-irradiated bFGF-hFLSCs. (lane 1) $\gamma$-irradiated hFLSCs transfected with control vectors; (lane 2) $\gamma$-irradiated bFGF- hFLSCs; (lane 3) A half amount of the lane 2. (C): The enzymelinked immunosorbent assay (ELISA) to bFGF showed that bFGF-hFLSCs could stably secret bFGF for one week. Values are presented as means \pm SD, $\mathrm{n}=4$.

doi:10.1371/journal.pone.0014457.g002

\section{Results}

\section{hFLSCs Used as Feeder Cells for Maintenance of H9 hES Cells}

We isolated and cultured hFLSCs from 14 weeks human fetal liver. About one week in culture the stromal cells migrated from the border of the tissue clumps (Fig. 1A), and it took two weeks for the cells to become confluent. After the primary and three subsequent passages, hFLSCs were adherent to be fusiform shape and highly uniform in morphology (Fig. 1B). As hFLSGs are propagated in culture for more than 30 passages (about 90 days), there are no obviously cell morphology changes. And then the irradiated hFLSCs were used for feeder cells to maintain H9 hES cells. Thus far, H9 cells were grown on hFLSCs for over 15 passages (about 100 days). We found that H9 hES cells colonies grown on hFLSGs were dense and compact, and they exhibited the typical morphology of hES cells (Fig. 1G). RT-PCR analysis showed positive expression of OCT-4, SOX-2 (Fig. 1D) when growing on hFLSCs for 10 passages (about 70 days). Flow cytometry analysis revealed that $\mathrm{H} 9 \mathrm{hES}$ cells grown on hFLSCs expressed hES specific markers OCT-4, SSEA-4, and TRA-1-60 (Fig. 1E). Immunocytochemical analysis also showed that H9 hES cells cultured on hFLSCs for 15 passages (about 100 days) expressed markers typical of hES cells, such as OCT-4 and SSEA-4 (Fig. 1F). The H9 hESCis cultured on hFLSCs had no differences with cultured on MEF (supporting information
Fig. S2A-C) Karyotyping of the hES cells showed that H9 hES cells grown on hFLSCs had normal female karyotype (supporting information Fig. S3).

\section{Maintenance of H9 hES cells on bFGF-hFLSCs Feeder Cells}

We have established the bFGF-hFLSGs by lentiviral system in our previous study [24]. After having been transfected with bFGF, the hFLSCs were sorted by FACS according to the intensity of eGFP expression (supporting information Fig. S4). The transduced hFLSCs with high eGFP expression were named as bFGF-hFLSCs and used as new feeder cells for maintenance of hES cells. As bFGF-hFLSCs were propagated in culture, there were also no obviously cell morphology changes. Flow cytometry analysis was used to characterize cell surface markers of bFGF-hFLSC, showing that the bFGF-hFLSCs were positive for some stromal progenitor markers, such as CD29, CD44, CD71, CD90, and CD105, but negative for CD34 and CD45 (supporting information Fig. S5), which was similar to the untransfected hFLSCs [24]. bFGF-hFLSCs maintained normal male karyotypes after 20 passages (about 60 days) (supporting information Fig. S6).

The irradiated bFGF-hFLSCs feeder cells showed the typical mesenchymal cell shape, and almost all cells expressed the eGFP (Fig. 2A). To determine the expression of bFGF in bFGF-hFLSC,s, western blotting was used to detect the expression level of bFGF 


\section{A}
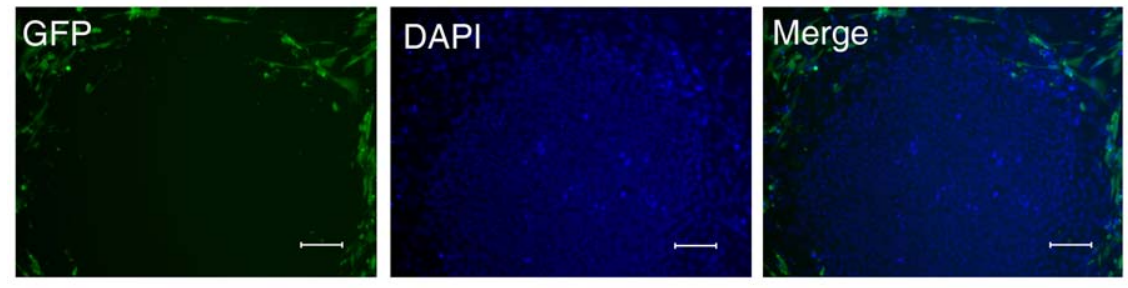

B
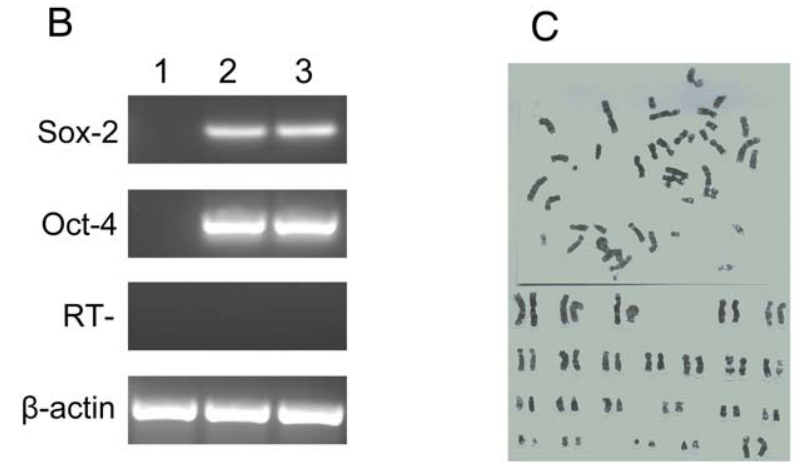

Figure 3. Characterization and karyotyping of H9 hES cells cultured on bFGF-hFLSCs feeder cells. (A): The H9 hES cells cultured on bFGF-hFLSCs imaged by fluorescence microscope. Bars: $100 \mu \mathrm{m}$. (B): RT-PCR analysis of H9 hES cells grown on bFGF-hFLSCs for 10 passages (about 70 days). 1: bFGF-hFLSCs feeder cells, 2: H9 hES cells cultured on MEF, H9 hES Cells cutred on bFGF-hFLSCs. (C): H9 hES cells grown on bFGF-hFLSCs for 15 passages (about 100 days) showed normal female karyotype $(46, \mathrm{XX})$. doi:10.1371/journal.pone.0014457.g003

protein in bFGF-hFLSCs feeders. As shown in Fig. 2B, there was high bFGF expression in bFGF-hFLSCs feeders. To measure bFGF in cell culture supernates, the quantikine bFGF immunoassay kit was used to determine values accurately. The results showed that soluble bFGF in culture medium of $\gamma$-irradiated bFGF-hFLSCs maintained in high level in about one week (Fig. 2C). The secreting bFGF from bFGF-hFLSCs feeder cells might replace the exogenous bFGF in hES cell culture.

To test whether bFGF-hFLSCs support undifferentiated growth of hES cells without supplementing with exogenous bFGF, we cultured H9 hES cells on bFGF-hFLSGs. Indeed, most H9 hES cells cultured with bFGF-expressing hFLSCs were maintained in an undifferentiated state. Undifferentiated hES colonies also could be found under fluorescence conditions for eGFP detection (Fig. 3A).

RT-PCR analysis showed positive expression of OCT-4, SOX2 (Fig. 3B) when H9 hES cells grown on bFGF-hFLSCs for 10 passages (about 70 days). Karyotype analysis showed that H9 hES cells grown on bFGF-hFLSGs had normal female karyotypes (Fig. 3C). The new culture system proved of supporting the culture of H9 hES cells and the expression of the specific markers OCT-4, SSEA-4, TRA-1-60 and TRA-1-81 was similar to cells grown on MEFs (Fig. 4). Currently, hES cells are commonly cultured on MEF feeders with $4 \mathrm{ng} / \mathrm{ml}$ exogenous bFGF in culture conditions. Our data suggested that without the exogenous bFGF, the fetal liver stromal cells with the bFGF transgene provided an environment to maintain hES cells for a long culture time.

\section{Embryoid Body-Mediated Differentiation of hES Cells Cultured on bFGF-hFLSCs}

The hES cells retained the capacity for extensive differentiation as indicated by analysis of ectoderm, mesoderm, and endoderm marker gene expression following EB formation. To determine the differentiation ability of $\mathrm{H} 9 \mathrm{hES}$ cells cultured on bFGF-hFLSCs in vitro, we used floating cultivation to form EBs [27]. After 6 days in suspension culture, H9 hES cells formed ball-shaped EBs (Fig. 5A). The EBs did not contain the eGFP-positive-hFLSCs feeder cells by examining with fluorescence microscopy. We transferred EBs to gelatin-coated plates and continued cultivation for another 10 days (Fig. 5B). Attached cells showed various types of morphologies, such as those resembling epithelial cells and fibroblast like cells (Fig. 5C, D). RT-PCR confirmed that these differentiated cells expressed human chorionic gonadotrophin (HCG, a marker of extraembryonic trophoblast), $\alpha$-fetoprotein (AFP, endoderm), cytokeratin 18 (CK 18, endoderm), BRACHYURY (mesoderm), and paired box 6 (PAX6, ectoderm), glial fibrillary acidic protein (GFAP, ectoderm) (Fig. 5E). In contrast, expression of OCT4 and SOX-2 was almost undetectable (Fig. 5E). The in vitro differentiation capability of $\mathrm{H} 9$ hES cells was similar to that cultured on MEF (supporting information Fig. S2D). Immunocytochemistry detected cells positive for $\beta$ III-tubulin (a marker of ectoderm), $\alpha$-smooth muscle actin $(\alpha$ SMA, mesoderm), and AFP (endoderm) (Fig. 5F). These data demonstrated that hES cells could differentiate into three germ layers in vitro. We subsequently tested long-term culture of H9 hES cells to 15 passages (about 100 days), morphologies of undifferentiated hES cell colonies were maintained as those cultured on MEFs feeders. Additionally, H9 hES cells cultured on bFGF-hFLSGs for 10 passages (about 70 days) were able to form teratoma comprising cell lineages of three embryonic germ layers in vivo in NOD-SCID mice (Fig. 5G).

\section{The FGF and IGF Related Receptors Expression in the hES} and hFLSCs Culture

There are four FGF receptors (FGFR 1-4). bFGF is related to FGFR1, which accounts for the high affinity of bFGF binding sites in the nucleus and cytoplasm [28]. Previous study suggest that FGF receptors may be important to hES cell culture systems, but 

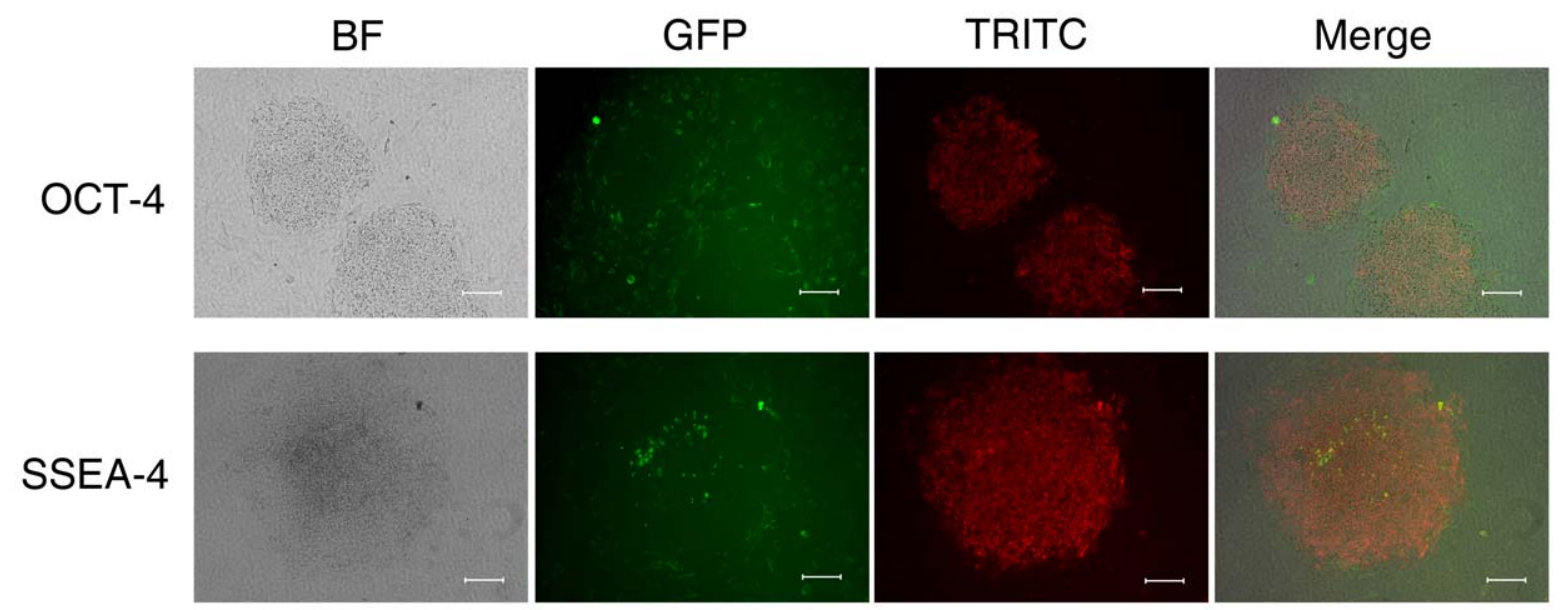

TRA-1-60
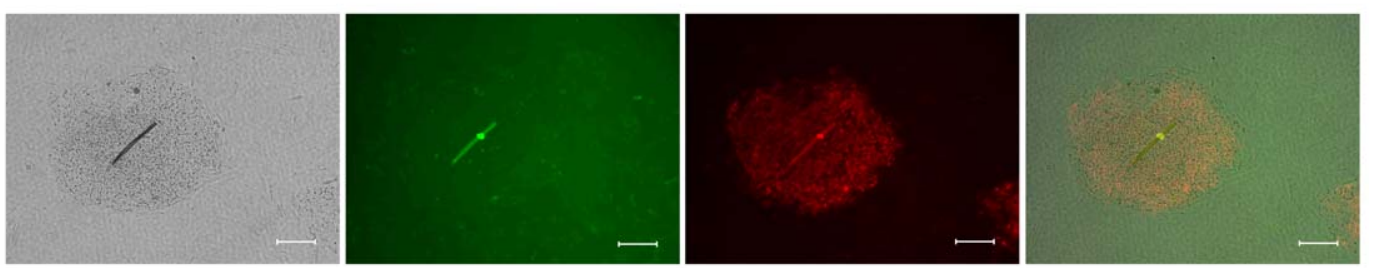

TRA-1-81
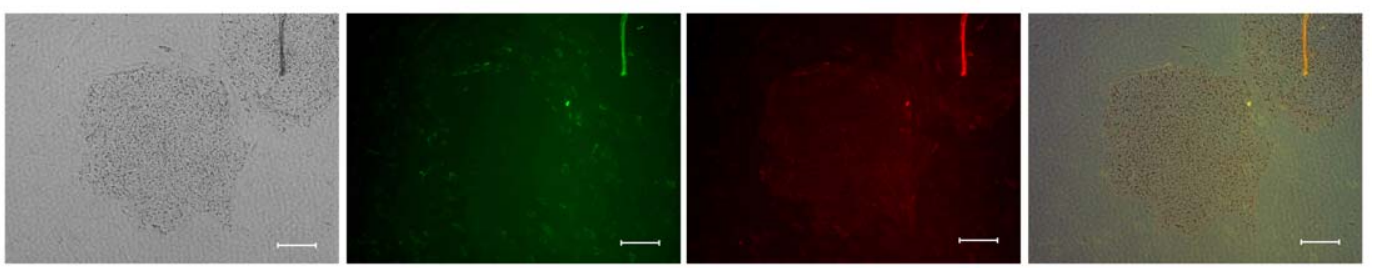

Figure 4. Immunocytochemistry for OCT-4, SSEA-4, TRA-1-60, TRA-1-81 of the H9 hES cells that cultured on bFGF-hFLSCs for 12 passages (about 80 days). Bars: $100 \mu \mathrm{m}$.

doi:10.1371/journal.pone.0014457.g004

are not dominantly expressed by the self-renewing, pluripotent human stem cells. However, IGF1R expression correlates with pluripotent stem cell markers and thereby underscores both the uniqueness and general importance of the IGF-2/IGF1R axis in hES cell lines [23]. So, in the present study, we investigated expression of FGFR1 and IGF1R to confirm the link between bFGF and IGF in the H9 hES cells and hFLSCs culture. As shown in Fig. 6A, the hFLSGs expressed FGFR1, and didn't express IGF1R. We also observed that IGF1R expressed exclusively within H9 hES cell colonies (Fig. 6B), while FGFR1 expression was limited to cells surrounding the H9 hES cell colonies (Fig. 6C). These results provided another example of bFGF's role in the stem cell niche underlining human feeder cells indirectly regulating hES cells.

bFGF-hFLSCs Expressed IGF-2 and Other Related Factors

Since bFGF is known to regulate IGF-1 [29] and IGF-2 [30], we examined the relative expression level of IGF-2 genes in bFGF-hFLSCs by RT-PCR and western blotting. The results showed that both the expression of bFGF and IGF-2 mRNA highly increased in bFGF-hFLSGs (Fig. 7A). Western blotting also showed that the IGF-2 protein was highly induced in bFGFhFLSCs (Fig. 7B). These data indicated that bFGF-hFLSCs produced adequate amounts of endogenous IGF-2 to maintain hES cells. To determine whether bFGF influences not only IGF-2, but also other related factors, we investigated the expression of IGF-1, TGF- $\beta 1$, IGF1R and FGFR1 by RT-PGR in bFGF-hFLSGs. TGF- $\beta 1$ expression was shown to be induced by bFGF transfection. These data suggested that bFGF-hFLSCs produced TGF- $\beta 1$ factors required by hES cells to maintain an undifferentiated state. And also FGFR1 and IGF1R expression of bFGF-hFLSCs was also higher than that of hFLSCs transfected with control vector.

Feeder-free maintenance of hES cells in bFGF-hFLSCs-CM

Many feeder-free hES cells culture systems is still based on the use of xenogenic MEF-CM. Only in very recent work have hES cells been maintained feeder free using chemically defined medium $[16,19]$. We therefore sought to determine whether H9 hES cells can be maintained pluripotent and feeder-free in bFGFhFLSCs-CM. H9 hES cells were maintained for 15 passages (about 100 days) feeder-free in bFGF-hFLSCs-CM. No differences in culture homeostasis were observed among hES cells maintained in bFGF-hFLSCs-CM versus MEF-GM and mTeSR1. Identical to H9 hES cells cultured in MEF-CM and mTeSR1, those maintained in bFGF-hFLSCs-GM retained typical hES cell morphology and expression of transcription factors Oct4 and Sox-2 (Fig. 7D). Similarly, both H9 hES cells expressed the the pluripotency associated surface markers SSEA-4 (Fig. 7E).

\section{Discussion}

Here we described a new population of hFLSCs that were capable of supporting the H9 hES cells expansion in vitro. We had 
A

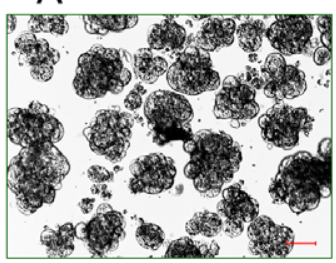

C

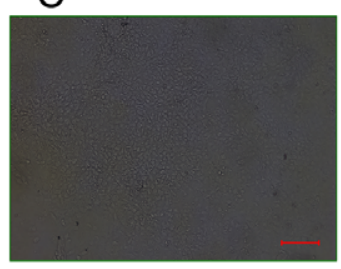

D

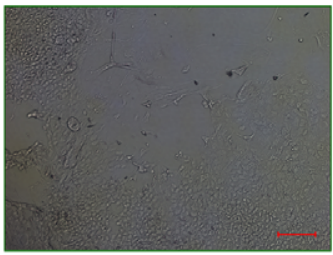

$\mathrm{F}$
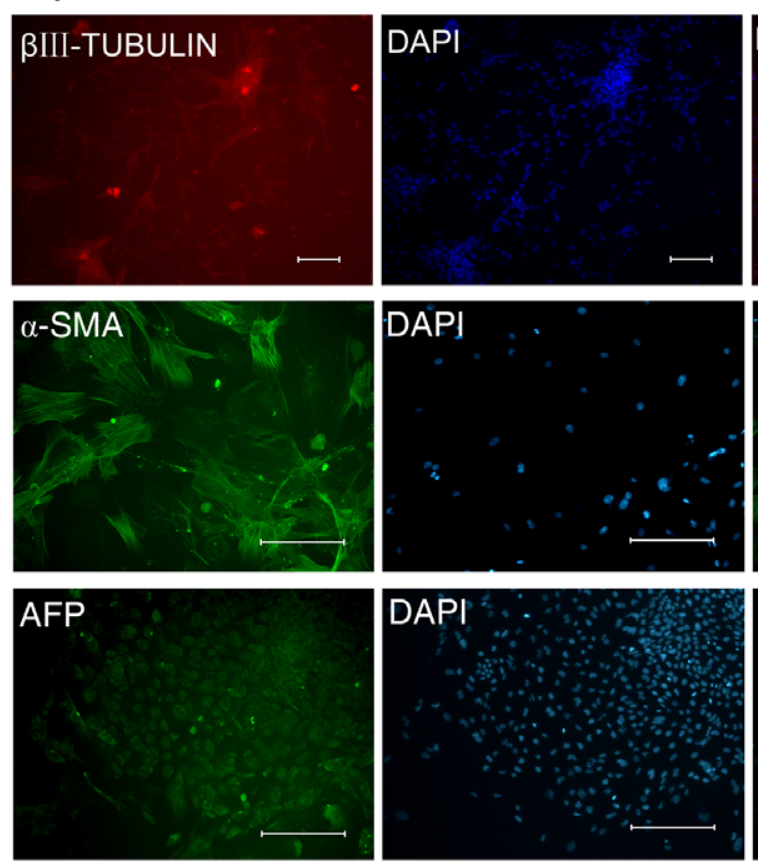
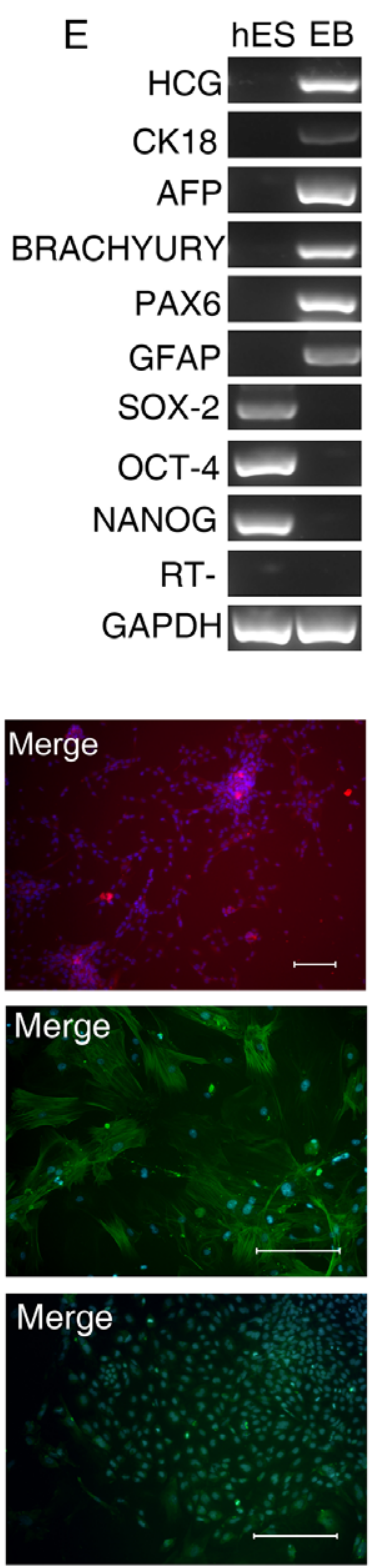

\section{G}

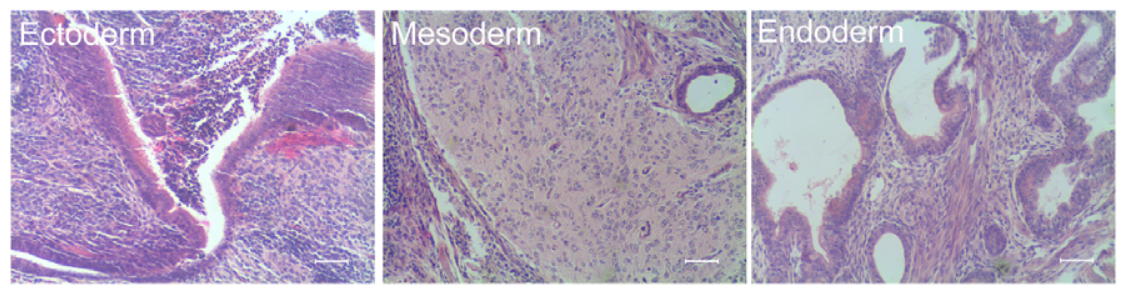

Figure 5. In vitro and in vivo differentiation of $\mathrm{H} 9$ hES cells cultured on bFGF-hFLSCs for 10 passages (about 70 days). (A): Floating culture of $\mathrm{H} 9 \mathrm{hES}$ cells at day 6. Bar: $100 \mu \mathrm{m}$. (B-D): Images of differentiated cells at day 10 (B), epithelial cells (C), fibroblast like cells (D). Bars: $100 \mu \mathrm{m}$. (E): RT-PCR analysis of various differentiation markers for the three germ layers and extraembryonic trophoblast. (F): Immunocytochemistry of AFP, aSMA, and $\beta$ III-TUBULIN. Nuclei were stained with DAPI (blue). Bars: $100 \mu \mathrm{m}$. (G): Teratoma formation. bFGF-hFLSCs-cultured H9 cells for 10 passages (about 70 days) form teratoma generating structures representative of three germ layers. Bars: $100 \mu \mathrm{m}$.

doi:10.1371/journal.pone.0014457.g005

cultured H9 hES cells through multiple passages while they retained stable expression of undifferentiated markers of hES cells, and a capacity to differentiate to three germ layer cells. We further showed that hFLSGs over-expressing bFGF could be used as a new feeder cells to maintain H9 hES cells without supplementing with any exogenous growth factors. And the conditioned medium of bFGF-hFLSCs could maintain the H9 hES cells under a feederfree conditions without supplementing with bFGF. Our results 

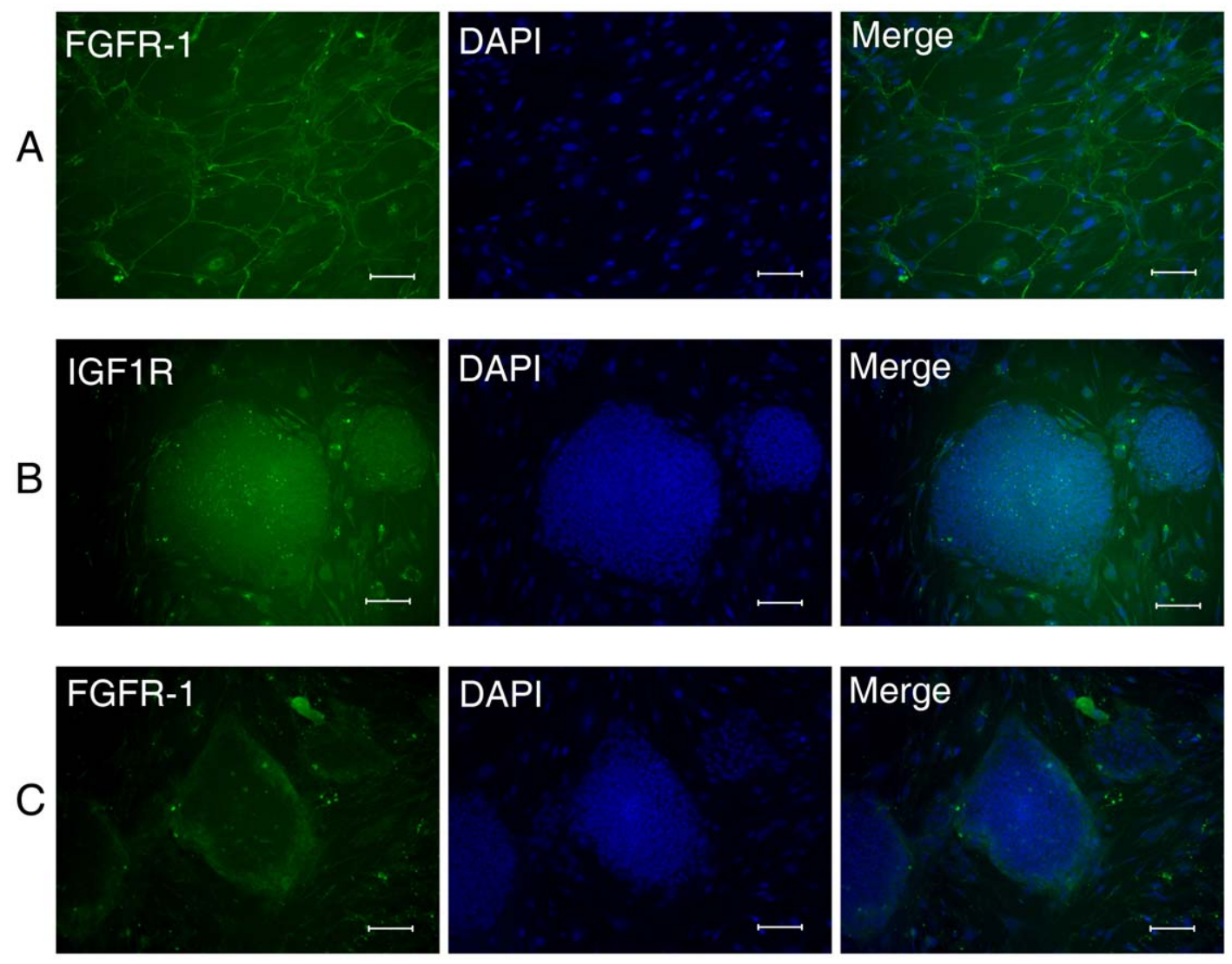

Figure 6. Immunocytochemistry for FGFR1 and IGF1R of the hFLSCs (A) and hES cells that cultured on hFLSCs (B,C). Nuclei were stained with DAPI (blue). Bars: $100 \mu \mathrm{m}$. doi:10.1371/journal.pone.0014457.g006

demonstrated that all undifferentiated H9 hES cells expressed IGF1R hFLSCs express FGFR1. And the bFGF-hFLSCs specifically expressed high levels of bFGF, IGF-2 and other related factors to support hES cells in culture. We suggested that bFGF-hFLSCs maintained H9 hES cells by establishing a stem cell niche through which supporting the self-renewal and pluripotency of hES cells.

Mouse feeder cells are associated with risks such as viral infection and pathogen transmission when hES cells are used in clinical trials. Various culture conditions have been developed to overcome these problems. Previous studies have used certain types of primary human cells, as well as commercially available cell lines, as feeder layers $[9,31,32,33]$. These studies all show that human feeder cells can be used to support hES cell growth and miantainenane. In our study, we isolated hFLSCs from 14 weeks fetal liver tissues, thus probably providing embryonic-like niche for hES cells. Our results showed that H9 hES cells can be maintained on hFLSCs feeder cells for over 15 passages (about 100 days). hFLSCs could be used as a new human feeder cell to support hES cells expansion in vitro.

One of the improved culture conditions is a feeder-free culture $[12,15]$. And several chemically defined culture mediums also are used to maintain hES cells $[17,19,34]$. One important issue is that these culture mediums are so expensive that they can't be used in large-scale expansion of hES cells for prospective clinical applications. It will be very important to find more economical hES cell culture methods.

As we have known, bFGF remains a necessary growth factor for the undifferentiated growth of hES cells. It regulates the expression of TGF $\beta 1$, Activin A and the BMP4 antagonist which are important for hES cell growth and self-renewal $[22,35]$. The fact that MEF and human feeder cell lines secrete varying amounts of bFGF may partially explain why different batches of MEFs and human feeder cell lines support hES cells differently [35]. Cai and colleagues generate immortalized feeder cells overexpressing Wnt3a that are supportive of hES cell expansion and pluripotency maintenance [36]. One fibroblast-like feeder cell line which differentiated spontaneously from hES cells secreting bFGF supported hES cell expansion particularly well up to passages 15 [37]. In this study about $11.66 \pm 0.23 \mathrm{pg} / \mathrm{ml}$ of FGF2 is detected in the germ layer derived fibroblast cells (GLDF) conditioned medium. These studies indicated that using gene modification feeder cells might improve the hES cell culture method. Our results showed that bFGF-hFLSCs secreted much higher bFGF than in the previous study [37]. We found that the maintenance of undifferentiated hES cells could be promoted by the bFGFhFLSCis without supplementing with growth factors. The hES cell colonies maintained on bFGF-hFLSCs showed less signs of morphological differentiation. The hES cells were positive for the pluripotent markers when maintained on bFGF-hFLSCs. hES cells were stably passaged for up to 15 passages (about 100 days) by co-culture with bFGF-hFLSCs.

Expression of bFGF in bFGF-hFLSCs feeder cells made the hES cell culture more economical where supplemental bFGF is not needed. It was quite evident that bFGF-hFLSGs cells presented to hES cell researchers with a novel feeder system for stable hES cell cultures. bFGF-hFLSCs were eased to culture for large scale, and enabled the development of goods mamufacturing 
A
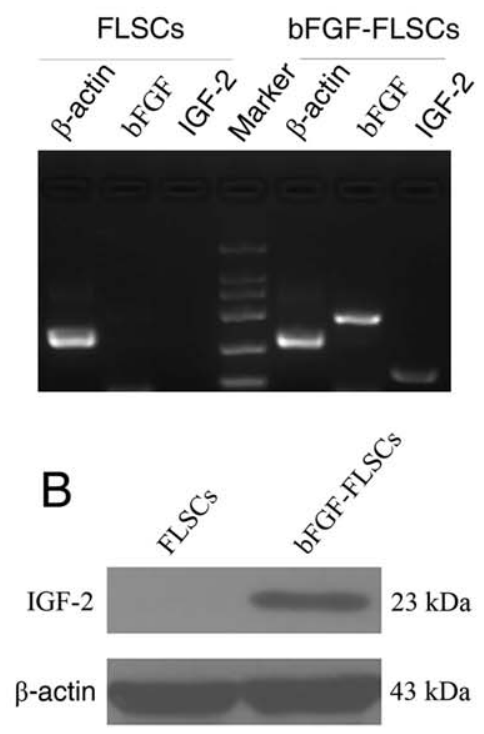

C

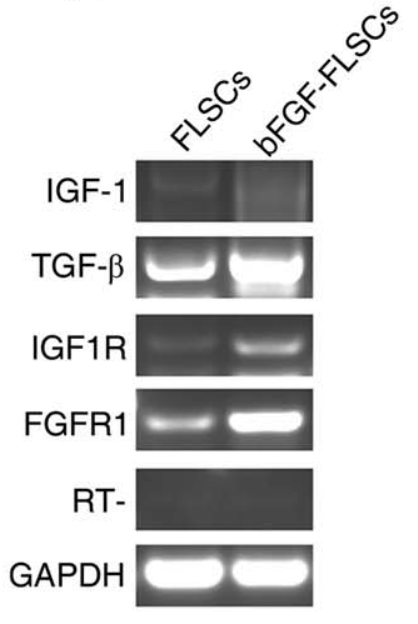

D

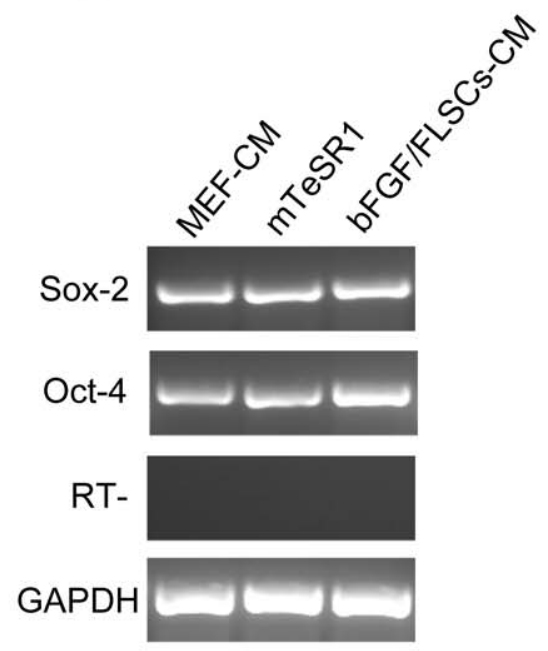

E

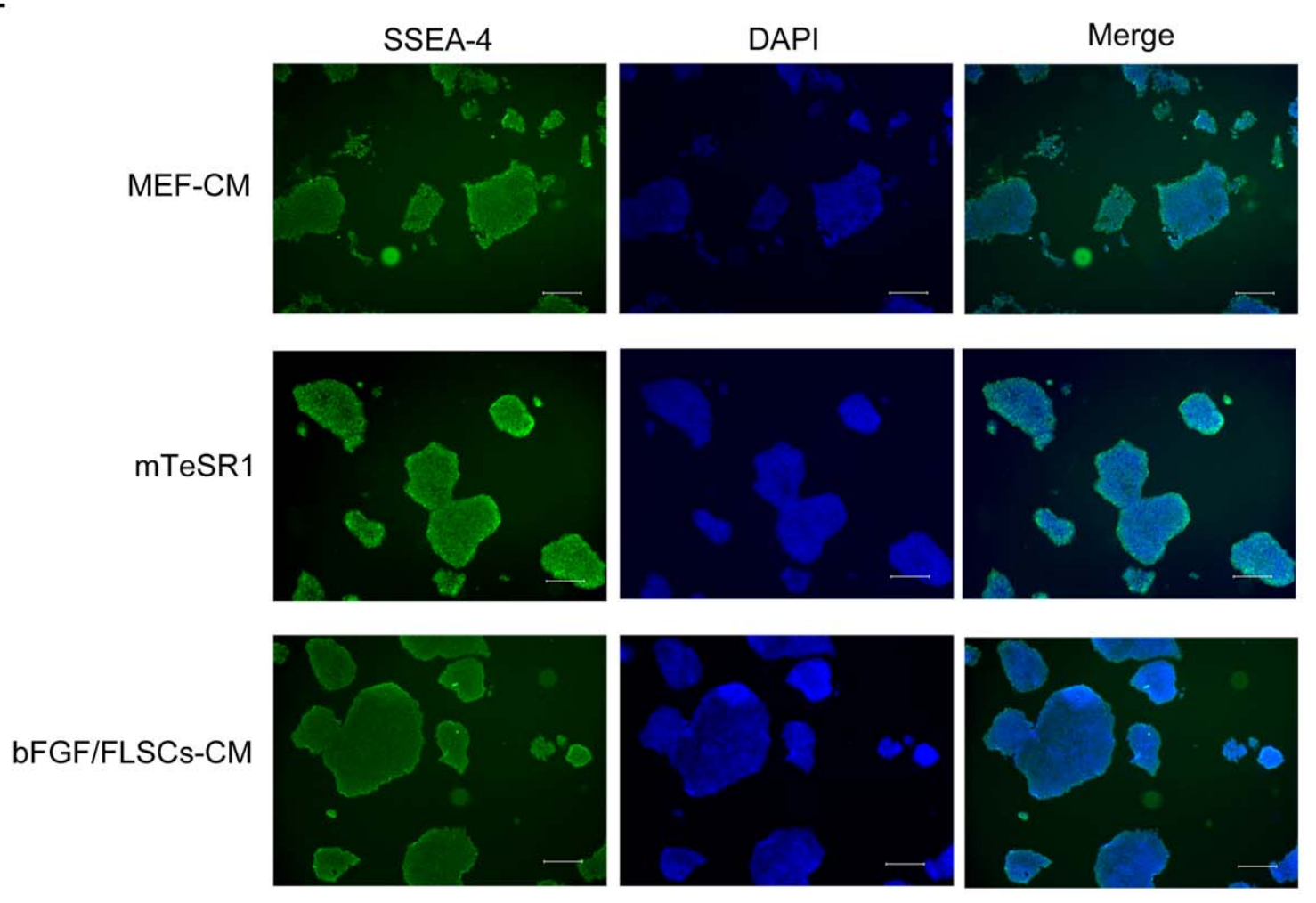

Figure 7. H9 hES cells could be maintained feeder-free with bFGF-hFLSCs-CM. (A): RT-PCR analysis of bFGF and IGF-2 gene expression in hFLSCs and bFGF-hFLSCs. (B): Western blotting analysis of IGF-2 gene expression in hFLSCs and bFGF-hFLSCs. (C): RT-PCR analysis of bFGF and IGF-2 related gene expression in hFLSCs and bFGF-hFLSCs. (D): RT-PCR analysis of H9 hES cells grown on MEF-CM, mTeSR1 and bFGF-hFLSCs-CM for 10 passages (about 70 days). (E): Immunophenotypic characterization of H9 hES cells maintained feeder-free with MEF-CM, mTeSR1 and bFGF-hFLSCsCM for 10 passages (about 70 days). Nuclei were stained with DAPI (blue). Bars: $250 \mu \mathrm{m}$. doi:10.1371/journal.pone.0014457.g007

practice (GMP) systems. bFGF-hFLSCs or its conditioned media could be an efficient alternative and useful to support the derivation and culture of new hES cell lines for clinical applications as comparable to hES cells cultured on MEFs.
Several recent studies have shown that IGF-2 play an important role in maintenance of hES cells $[23,34,38]$. IGF-2 has been suggested to play important roles in embryonic but not adult growth and development $[39,40]$. IGF-2 has also been used to 
establish pluripotential cell lines [41] and maintain undifferentiated stem cells from the inner cell mass in culture $[41,42]$. In a previous study [43], the author identified IGF-2 expressed in a novel fetal liver cell populations as a novel stem cell growth factor. Because IGF-2 has pleiotropic effects, it may have the potential to act on a broader spectrum of stem cells, both ex vivo and in vivo. One study focus on FGF receptor expression profiles in hES cell cultures, and suggest that bFGF may stimulate undifferentiated hES cell proliferation directly or indirectly [44]. In another study, a simultaneous interrogation of 42 receptor tyrosine kinases (RTKs) in hES cells following stimulation with MEF conditioned medium (CM) reveal rapid and prominent tyrosine phosphorylation of insulin receptor (IR) and IGF1R [34]. In the most recent study, the authors showed that hES cells spontaneously and continuously differentiate into hdFs, providing a continuous source of endogenous hES cell supportive factors, including IGF-2 and a host of TGF- $\beta$ family of factors and other ligands [23]. On the whole, these studies demonstrate a direct role of the IGF-2/ IGF1R axis on hES cell self-renewal and pluripotency.

In the present study, we suggested bFGF and IGF-2 as the principal growth factor produced by bFGF-hFLSCs that supports expansion of H9 hES cells. And our results showed that hFLSGs expressed FGFR1, which could be stimulated by the bFGF secreted by bFGF-hFLSCs through autocrine and paracrine model. And after transducing with bFGF, the expression of IGF1R, FGFR1, and TGF- $\beta 1$ in bFGF-hFLSCs was much higher than in hFLSCs. This positive model made bFGF-hFLSCs express sufficient IGF-2 and TGF- $\beta 1$ to support growth and maintenance of hES cells through IGF-2/IGF1R axis and other undefined signal pathways. bFGF-hFLSCs feeder cells were central to establishing the signaling network among bFGF, IGF-2, and TGF- $\beta$, and thereby probably providing the framework in which hES cells were instructed to self-renew or to differentiate.

The concept that a regulatory niche creates an essential and supportive microenvironment for stem cells has been well established in several organisms and lineages [45]. In our previous study, we have used hFLSCs expressing hypoxia inducible factor $1 \alpha(\mathrm{HIF}-1 \alpha)$ to maintain self-renewal and pluripotency of hES cells [46]. Our present study also provided evidences that gene modified hFLSCs generated a stem cell niche in vitro that could support the growth and pluripotency of $\mathrm{H} 9 \mathrm{hES}$ cells. Our in vitro hES cells culture system using bFGF-hFLSCs as feeder cells provided an opportunity to elucidate the fundamental elements tightly controlling hES cell self-renewal and pluripotency.

In our present study, we aimed at determining whether the hES cells can be maintained pluripotent using bFGF-hFLSCs-CM rather than xenogenic MEF-CM. Similar to feeder-free culture in MEF-GM and mTeSR1, H9 hES cells can be equally maintained stable and pluripotent for over 15 passages (about 100 days). H9 hES cells maintained in bFGF-hFLSCs-CM without supplementing with bFGF retained typical morphology, expression of surface markers and transcription factors associated with pluripotency The conditioned medium of bFGF-hFLSCs could be used to develop a new hES cell feeder-free culture condition.

\section{References}

1. Thomson JA, Itskovitz-Eldor J, Shapiro SS, Waknitz MA, Swiergiel JJ, et al. (1998) Embryonic stem cell lines derived from human blastocysts. Science 282: 1145-1147.

2. Reubinoff BE, Pera MF, Fong CY, Trounson A, Bongso A (2000) Embryonic stem cell lines from human blastocysts: somatic differentiation in vitro. Nat Biotechnol 18: 399-404.

3. Wobus AM, Boheler KR (2005) Embryonic stem cells: prospects for developmental biology and cell therapy. Physiol Rev 85: 635-678.

4. Keller G (2005) Embryonic stem cell differentiation: emergence of a new era in biology and medicine. Genes Dev 19: 1129-1155.
In conclusion, we isolated a new human feeder cell for maintenance of $\mathrm{H} 9 \mathrm{hES}$ cells. And then, we established transgenic cell lines - bFGF-hFLSCs that stably express bFGF, which could be used as feeder cells culturing H9 hES cells without supplementing with exogenous growth factors. More importantly of the bFGF-hFLSCs-CM could maintain H9 hES cell pluripotency in feeder-free culture conditions. bFGF-hFLSCs had great potential as feeders for maintaining hES cells more safely and economically.

\section{Supporting Information}

Figure S1 The construction of lentiviral vector pBPLV. Found at: doi:10.1371/journal.pone.0014457.s001 (0.88 MB TIF)

Figure S2 H9 hES cells cultured on MEF. (A): Morphology of MEF. Bars $=100 \mu \mathrm{m}$. (B): Morphology of H9 hES cells cultured on MEF. Bars $=100 \mu \mathrm{m}$. $(\mathrm{C})$ : Immunophenotypic characterization of H9 hES cells cultured on MEF. Nuclei were stained with DAPI (blue). Bars: $100 \mu \mathrm{m}$. (D): In vitro differentiation of H9 hES cells cultured on MEF. RT-PCR analysis of various differentiation markers for the three germ layers and extraembryonic trophoblast. Found at: doi:10.1371/journal.pone.0014457.s002 (2.50 MB TIF)

Figure S3 Karyotype analysis of H9 hES cells expanded on hFLSCs feeder cells for 15 passages (about 100 days) represented normal 46, XX karyotype.

Found at: doi:10.1371/journal.pone.0014457.s003 (1.12 MB TIF)

Figure S4 Transfected hFLSCs with low and high eGFP expression were sorted by fluorescence-activated cell sorting (FACS). The zonation of the selected transfected hFLSCs, P3 reprsented the hFLSGs with low eGFP expression, P4 represented hFLSCs with high eGFP expression.

Found at: doi:10.1371/journal.pone.0014457.s004 (4.29 MB TIF)

Figure S5 Flow cytometry analysis of bFGF-hFLSCs for the presence of CD29, CD44, CD90, and CD105, and negative for CD11b, CD34, CD45 and CD144. The green line represented the staining with the isotype control, and the red line showed staining with specific antibodies.

Found at: doi:10.1371/journal.pone.0014457.s005 (1.02 MB TIF)

Figure S6 Karyotype analysis of bFGF-hFLSCs for 20 passages (about 60 days) represented normal 46, XY karyotype.

Found at: doi:10.1371/journal.pone.0014457.s006 (8.67 MB TIF)

\section{Acknowledgments}

We thank Prof. Luigi Naldiai (Vita Salute San Raffaele University, Italy) for the gift of pBPLV lentiviral vector plasmids.

\section{Author Contributions}

Conceived and designed the experiments: JX YW WY XP. Performed the experiments: JX YW PZ LH. Analyzed the data: JX YW PZ WY XP. Contributed reagents/materials/analysis tools: LH XN. Wrote the paper: JX WY XP.

5. Martin MJ, Muotri A, Gage F, Varki A (2005) Human embryonic stem cells express an immunogenic nonhuman sialic acid. Nature Medicine 11: 228-232.

6. Richards M, Fong CY, Chan WK, Wong PC, Bongso A (2002) Human feeders support prolonged undifferentiated growth of human inner cell masses and embryonic stem cells. Nat Biotechnol 20: 933-936.

7. Cheng L, Hammond H, Ye Z, Zhan X, Dravid G (2003) Human adult marrow cells support prolonged expansion of human embryonic stem cells in culture. Stem Cells 21: 131-142.

8. Amit M, Margulets V, Segev H, Shariki K, Laevsky I, et al. (2003) Human feeder layers for human embryonic stem cells. Biol Reprod 68: 2150-2156. 
9. Richards M, Tan S, Fong CY, Biswas A, Chan WK, et al. (2003) Comparative evaluation of various human feeders for prolonged undifferentiated growth of human embryonic stem cells. Stem Cells 21: 546-556.

10. Miyamoto K, Hayashi K, Suzuki T, Ichihara S, Yamada T, et al. (2004) Human placenta feeder layers support undifferentiated growth of primate embryonic stem cells. Stem Cells 22: 433-440.

11. Rajala K, Hakala H, Panula S, Aivio S, Pihlajamaki H, et al. (2007) Testing of nine different xeno-free culture media for human embryonic stem cell cultures. Hum Reprod 22: 1231-1238.

12. Xu C, Inokuma MS, Denham J, Golds K, Kundu P, et al. (2001) Feeder-free growth of undifferentiated human embryonic stem cells. Nat Biotechnol 19: 971-974.

13. Sato N, Meijer L, Skaltsounis L, Greengard P, Brivanlou AH (2004) Maintenance of pluripotency in human and mouse embryonic stem cells through activation of Wnt signaling by a pharmacological GSK-3-specific inhibitor. Nat Med 10: 55-63.

14. Xu RH, Peck RM, Li DS, Feng X, Ludwig T, et al. (2005) Basic FGF and suppression of BMP signaling sustain undifferentiated proliferation of human ES cells. Nat Methods 2: 185-190.

15. Wang GW, Zhang H, Zhao Y, Li H, Cai J, et al. (2005) Noggin and bFGF cooperate to maintain the pluripotency of human embryonic stem cells in the absence of feeder layers. Biochemical and Biophysical Research Communications 330: 934-942.

16. Lu J, Hou RH, Booth CJ, Yang SH, Snyder M (2006) Defined culture conditions of human embryonic stem cells. Proceedings of the National Academy of Sciences of the United States of America 103: 5688-5693.

17. Ludwig TE, Levenstein ME, Jones JM, Berggren WT, Mitchen ER, et al. (2006) Derivation of human embryonic stem cells in defined conditions. Nat Biotechnol 24: 185-187.

18. Yao S, Chen S, Clark J, Hao E, Beattie GM, et al. (2006) Long-term self-renewal and directed differentiation of human embryonic stem cells in chemically defined conditions. Proc Natl Acad Sci U S A 103: 6907-6912.

19. Furue MK, Na J, Jackson JP, Okamoto T, Jones M, et al. (2008) Heparin promotes the growth of human embryonic stem cells in a defined serum-free medium. Proc Natl Acad Sci U S A 105: 13409-13414.

20. Chambers I, Smith A (2004) Self-renewal of teratocarcinoma and embryonic stem cells. Oncogene 23: 7150-7160.

21. Levenstein ME, Ludwig TE, Xu RH, Llanas RA, VanDenHeuvel-Kramer K, et al. (2006) Basic fibroblast growth factor support of human embryonic stem cell self-renewal. Stem Cells 24: 568-574.

22. Greber B, Lehrach H, Adjaye J (2007) Fibroblast growth factor 2 modulates transforming growth factor beta signaling in mouse embryonic fibroblasts and human ESCs (hESCs) to support hESC self-renewal. Stem Cells 25: 455-464.

23. Bendall SC, Stewart MH, Menendez P, George D, Vijayaragavan K, et al. (2007) IGF and FGF cooperatively establish the regulatory stem cell niche of pluripotent human cells in vitro. Nature 448: 1015-1021.

24. XiJF, Wang YF, Zhang P, Yuan HF, Shi SS, et al. (2007) Establishment of fetal liver stroma cell lines which stably express basic fibroblast growth factor by lentiviral system. Progress in Biochemistry and Biophysics 34: 207-214.

25. Amendola M, Venneri MA, Biffi A, Vigna E, Naldini L (2005) Coordinate dualgene transgenesis by lentiviral vectors carrying synthetic bidirectional promoters. Nature Biotechnology 23: 108-116.

26. Braam SR, Denning C, Matsa E, Young LE, Passier R, et al. (2008) Feeder-free culture of human embryonic stem cells in conditioned medium for efficient genetic modification. Nat Protocols 3: 1435-1443.

27. Takahashi K, Tanabe K, Ohnuki M, Narita M, Ichisaka T, et al. (2007) Induction of pluripotent stem cells from adult human fibroblasts by defined factors. Cell 131: 861-872.
28. Peng H, Myers J, Fang X, Stachowiak EK, Maher PA, et al. (2002) Integrative nuclear FGFR1 signaling (INFS) pathway mediates activation of the tyrosine hydroxylase gene by angiotensin II, depolarization and protein kinase C. J Neurochem 81: 506-524.

29. Pons S, Torres-Aleman I (1992) Basic fibroblast growth factor modulates insulinlike growth factor-I, its receptor, and its binding proteins in hypothalamic cell cultures. Endocrinology 131: 2271-2278.

30. Gabbitas B, Pash J, Canalis E (1994) Regulation of insulin-like growth factor-II synthesis in bone cell cultures by skeletal growth factors. Endocrinology 135: 284-289.

31. Choo A, Ngo AS, Ding V, Oh S, Kiang LS (2008) Autogeneic feeders for the culture of undifferentiated human embryonic stem cells in feeder and feeder-free conditions. Methods Cell Biol 86: 15-28.

32. Zhou HS, Yong J, Sun XM, Wang CY, Yang WF, et al. (2008) A human endothelial cell feeder system that efficiently supports the undifferentiated growth of mouse embryonic stem cells. Differentiation 76: 923-930.

33. Chen HF, Chuang CY, Shieh YK, Chang HW, Ho HN, et al. (2009) Novel autogenic feeders derived from human embryonic stem cells (hESCs) support an undifferentiated status of hESCs in xeno-free culture conditions. Human Reproduction 24: 1114-1125.

34. Wang L, Schuiz TC, Sherrer ES, Dauphin DS, Shin S, et al. (2007) Self-renewal of human embryonic stem cells requires insuhn-like growth factor-1 receptor and ERBB2 receptor signaling. Blood 110: 4111-4119.

35. Eiselleova L, Peterkova I, Neradil J, Slaninova I, Hampl A, et al. (2008) Comparative study of mouse and human feeder cells for human embryonic stem cells. Int J Dev Biol 52: 353-363.

36. Cai L, Ye Z, Zhou BY, Mali P, Zhou C, et al. (2007) Promoting human embryonic stem cell renewal or differentiation by modulating Wnt signal and culture conditions. Cell Res 17: 62-72.

37. Saxena S, Hanwate M, Deb K, Sharma V, Totey S (2008) FGF2 secreting human fibroblast feeder cells: a novel culture system for human embryonic stem cells. Mol Reprod Dev 75: 1523-1532.

38. Montes R, Ligero G, Sanchez L, Catalina P, de la Cueva T, et al, (2009) Feederfree maintenance of hESCs in mesenchymal stem cell-conditioned media: distinct requirements for TGF-beta and IGF-II. Cell Research 19: 698-709.

39. Baker J, Liu JP, Robertson EJ, Efstratiadis A (1993) Role of insulin-like growth factors in embryonic and postnatal growth. Cell 75: 73-82.

40. O'Dell SD, Day IN (1998) Insulin-like growth factor II (IGF-II). Int J Biochem Cell Biol 30: 767-771.

41. Takahashi A, Takahashi Y, Matsumoto K, Miyata K (1995) Synergistic effects of insulin-like growth-factor-II (IGF-II) with leukemia inhibiting factor (LIF) on establishment of rat pluripotential cell-lines. Journal of Veterinary Medical Science 57: 553-556.

42. Newman-Smith ED, Werb Z (1995) Stem cell defects in parthenogenetic periimplantation embryos. Development 121: 2069-2077.

43. Zhang CG, Lodish HF (2004) Insulin-like growth factor 2 expressed in a novel fetal liver cell population is a growth factor for hematopoietic stem cells. Blood 103: 2513-2521.

44. Dvorak P, Dvorakova D, Koskova S, Vodinska M, Najvirtova M, et al. (2005) Expression and potential role of fibroblast growth factor 2 and its receptors in human embryonic stem cells. Stem Cells 23: 1200-1211.

45. Scadden DT (2006) The stem-cell niche as an entity of action. Nature 441: 1075-1079.

46. Ji L, Liu YX, Yang C, Yue W, Shi SS, et al. (2009) Self-renewal and pluripotency is maintained in human embryonic stem cells by co-culture with human fetal liver stromal cells expressing hypoxia inducible factor 1alpha. J Cell Physiol 221: 54 66 . 